\title{
Chronic Psychological Stress Induced Microbial Imbalance (Dysbiosis) Mediated Auto-Immune Diseases - A Current Concept
}

\author{
Shrihari TG* \\ Department of Oral Medicine and Oral Oncology, Krishnadevaraya College of Dental Sciences, India
}

*Corresponding author: Shrihari TG, Assistant professor, Department of Oral Medicine and Oral Oncology, Krishnadevaraya College of Dental Sciences, Bengaluru-562157, India

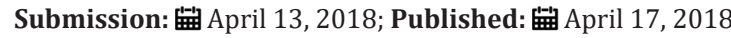

\section{Introduction}

Chronic psychological stress induced release of $\mathrm{CRH}$ (corticotrophic releasing hormone) from hypothalamus activates HPA-axis (hypothalamo pituitary adrenal axis) through autonomic nervous system release cortisol, ACTH (Adrenocorticotrophic releasing hormone), and noradrenaline neuropeptides. These neuropeptides activates inflammatory mediators such as IL- $1 \beta$, TNF- $\alpha$, IL-6, pro-inflammatory cytokines and COX-2 inflammatory mediator from inflammatory cells (6-9).

Role of Psychological Stress in Microbial Imbalance and Autoimmunity

Chronic psychological stress mediated release of neuropeptide's such as cortisol, ACTH, and noradrenaline results in altered oral and gut micro flora consists of bacterias, viruses, fungi, protozoa, known as dysbiosis [1-5]. These altered microflora is recognized by PAMP (pathogen associated molecular patterns) belongs to toll like receptors (TLR) present on immune cells such as macrophages, dendritic cells, T and B lymphocytes activate NF$\mathrm{kB}$ a key transcription factor involved in conversion of Th1 to Th2 lymphocytic type, Th17 cells involved in immunomodulation and chronic inflammation [6-8]. Tregs (regulatory T cells ) alteration otherwise involved in self tolerance and immune homeostasis, activation of matrix metalloproteases (mmps) involved in tissue damage and cell proliferation by growth factors such as EGF, VEGF, FGF, all these changes leads to autoimmune diseases.

\section{References}

1. Baohong Wang, Mingfei Yao, LongxianLv, Zongxin Ling, Lanjuan Li (2017) The Human Microbiotain Health and Disease. Engineering 3(1): 71-82.

2. Franzosa EA, Morgan XC, Segata N, Waldron L, Reyes J, et al. (2014) Relating the metatranscriptome and metagenome of the human gut. Proc Natl Acad Sci U S A 111(22): E2329-E2338.

3. Yuichiro Yamashiro (2017) Gut Microbiota in Health and Disease. Ann Nutr Metab 71(3-4): 242-246.

4. Burcelin R (2016) Gut microbiota and immune crosstalk in metabolic disease. Mol Metab 5(9): 771-781.

5. Ursell LK, Haiser HJ, Van Treuren W, Garg N, Reddivari L, et al. (2014) The intestinal metabolome: an intersection between microbiota and host. Gastroenterology 146(6): 1470-1476.

6. Shrihari TG (2017) Quantum healing approach to new generation of holistic healing. Transl Med 7(3): 198.

7. Ljudmila stojanovich (2010) Stress and autoimmunity. Autoimmun Rev 9(5): A271-A276.

8. Stojanovich L, Marisavijevich D (2008) Stress as a trigger of autoimmune disease. Autoimmun Rev 7(3): 209-213.

9. Priyadarshini S, Palok A (2012) Effects of psychological stress on innate immunity and metabolism in humans: A systematic analysis. Plos One 7(9): 8-15.

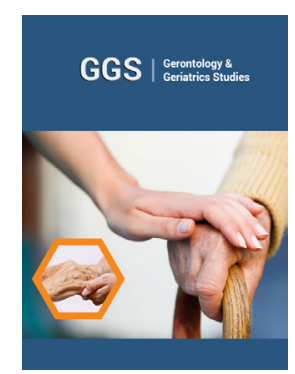

\section{Gerontology \& Geriatrics Studies}

\section{Benefits of Publishing with us}

- High-level peer review and editorial services

- Freely accessible online immediately upon publication

- Authors retain the copyright to their work

- Licensing it under a Creative Commons license

- Visibility through different online platforms 